\title{
Do antihypertensive drugs precipitate diabetes?
}

\author{
C BENGTSSON, G BLOHMÉ, L LAPIDUS, O LINDQUIST, H LUNDGREN, E NYSTRÖM, \\ K PETERSEN, J A SIGURDSSON
}

\begin{abstract}
A longitudinal population study of 1462 women aged 38-60 was carried out from 1968-9 to $1980-1$ in Gothenburg, Sweden. The initial and follow up examinations included questions concerning history of diabetes and antihypertensive treatment. A considerably increased risk of developing diabetes was observed for subjects with hypertension taking diuretics ( 895 patient years), subjects taking $\beta$ blockers (682 patient years), and subjects taking a combination of diuretics and $\beta$ blockers (281 patient years) compared with subjects not taking antihypertensive drugs (13 855 control years). When diuretics and $\beta$ blockers were compared no difference was found in relative risk.

Despite this increased risk, and because little is known about the relation between other forms of antihypertensive treatment and diabetes, diuretics and $\beta$ blockers should remain the treatments of choice in arterial hypertension.
\end{abstract}

\section{Introduction}

Although the development of diabetes has been postulated to be a possible side effect of diuretic treatment, no study has been able to show definitely whether there is a causal relation between diuretics and diabetes. In addition, some studies have indicated an increased incidence of diabetes in patients taking $\beta$ blockers. ${ }^{12}$ If the incidence of diabetes is increased in subjects taking different types of antihypertensive drugs the reason might be an association between the antihypertensive state and diabetes rather than between antihypertensive drugs and diabetes. We studied the incidence of diabetes over 12 years in a defined population sample. We compared subjects taking antihypertensive drugs with those not taking them. A further subdivision was made to compare subjects taking diuretics with subjects taking $\beta$ blockers.

\section{Patients and methods}

A population study of 1462 women aged $38,46,50,54$, or 60 was carried out in Gothenburg, Sweden, in 1968-9 (table I). Owing to the method of sampling and a high participation rate $(90.1 \%)$ the participants were representative of women of the ages studied in the general population. ${ }^{3}$ The population sample was studied again in $1974-5^{4}$ and $1980-1,{ }^{5}$ as table I shows. The present study deals with the 12 years' follow up between 1968-9 and 1980-1. Information was

Department of Medicine II, Sahlgrenska Hospital, Gothenburg University, S-413 45 Gothenburg, Sweden

C BENGTSSON, MD, associate professor

G BLOHMÉ, MD, associate professor

L LAPIDUS, MD, registrar

O LINDQUIST, MD, associate professor

E NYSTRÖM, MD, associate professor

$\mathrm{K}$ PETERSEN, MD, registrar

J A SIGURDSSON, MD, general practitioner

Health Centre, S-448 03 Floda, Sweden

H LUNDGREN, MD, general practitioner

Correspondence to: Dr C Bengtsson. obtained about antihypertensive treatment and prevalence of diabetes by telephone interview or letter from most of the refusers in the follow up studies and most of those who had moved from the area. Thus we succeeded in interviewing 1406 women (1302 participants) concerning antihypertensive treatment and diabetes in the follow up study in $1974-5$ (97.9\% of all survivors) and 1351 women (1154 participants) in $1980-1$ ( $97.4 \%$ of all survivors). Women who died during the six years between 1968-9 and 1974-5 $(n=26)$ or between 1974-5 and 1980-1 $(n=49)$ were excluded from analysis of the respective six year period. In none of the women who died had diabetes been diagnosed between her last participation in the population study and her death. Non-participants in the follow up studies from whom no information could be obtained were also excluded.

TABLE I-Number ( $\%$ ) of participants of each age taking part in each step of a longitudinal study of women in Gothenburg. Percentages shown for 1974-5 and 1980-1 were calculated as a proportion of those investigated in 1968-9

\begin{tabular}{rrrrr}
\hline $\begin{array}{c}\text { Year } \\
\text { of } \\
\text { birth }\end{array}$ & $\begin{array}{c}\text { Invited } \\
\text { in } \\
1968-9\end{array}$ & $1968-9$ & $1974-5$ & $1980-1$ \\
\hline 1930 & 407 & $372(91 \cdot 4)$ & $336(90 \cdot 3)$ & $308(82 \cdot 8)$ \\
1922 & 479 & $431(90 \cdot 0)$ & $387(89 \cdot 8)$ & $332(77 \cdot 0)$ \\
1918 & 436 & $398(91 \cdot 3)$ & $351(88 \cdot 2)$ & $325(81 \cdot 7)$ \\
1914 & 203 & $180(88.7)$ & $163(90 \cdot 6)$ & $140(77 \cdot 8)$ \\
1908 & 97 & $81(83 \cdot 5)$ & $65(80 \cdot 2)$ & $49(60 \cdot 5)$ \\
\hline Total & 1622 & $1462(90 \cdot 1)$ & $1302(89 \cdot 1)$ & $1154(78 \cdot 9)$ \\
\hline
\end{tabular}

Detailed information about antihypertensive t:eatment being received in the population sample at the time of each of the three studies has been reported previously. ${ }^{5}$ Twelve women in whom diabetes had already been diagnosed at the beginning of the study in 1968-9 were excluded from the start.

Table II shows mean values of fasting blood glucose concentration and body mass index, as initially recorded (in 1968-9), in women who at follow up in 1974-5 or 1980-1, or on both occasions, were taking a diuretic as a sole drug, a $\beta$ blocker as a sole drug, or the combination of a diuretic and a $\beta$ blocker. It compares these findings with those from women who were not taking antihypertensive drugs on either occasion. Differences were observed between women taking antihypertensive drugs and those not, but there were no obvious differences between women taking diuretics and those taking $\beta$ blockers or the combination. There was some tendency towards slightly higher blood glucose concentrations in women who received $\beta$ blockers and slightly higher body mass index in women who received diuretics (non-significant differences).

A family history of diabetes (among parents or brothers or sisters) was about equally common in all groups: 16 of 84 women $(19 \%)$ taking a diuretic as a sole drug in $1974-5$ or $1980-1$, or both, reported a family history of diabetes compared with $23(23 \%)$ of 98 taking a $\beta$ blocker, nine $(15 \%)$ of 59 taking a diuretic and a $\beta$ blocker in combination, and $132(14 \%)$ of 920 not taking antihypertensive drugs in either 1974-5 or 1980-1 (non-significant differences between the groups of women taking different drugs or combination).

In each of the three studies (1968-9, 1974-5, and 1980-1) the women were interviewed and examined in a comprehensive way. ${ }^{3-5}$ The interview included questions about history of diabetes and antihypertensive treatment. In patients with diabetes the time when the diagnosis was settled was recorded and type of antidiabetic treatment registered. Urine was tested for glucose. Blood glucose concentration was determined from venous blood with the patient in the fasting state. Women with blood glucose concentrations of $6.0 \mathrm{mmol} / 1(108 \mathrm{mg} / 100 \mathrm{ml})$ or more who were not known to have diabetes were referred to a special diabetes unit for further examination. A subject was defined as having diabetes if this had been diagnosed by a doctor or if two fasting venous or capillary whole blood samples 
TABLE II-Mean (SD) initial fasting blood glucose concentration and body mass index (recorded in 1968-9) in women taking a diuretic or a $\beta$ blocker as a sole antihypertensive drug or a combination of a diuretic and a $\beta$ blocker at the time of study in 1974-5 or 1980-1, or on both occasions, and in women not taking antihypertensive drugs in either $1974-5$ or $1980-1$

\begin{tabular}{|c|c|c|c|c|c|c|c|c|}
\hline \multirow{2}{*}{ Initial age (years) } & \multicolumn{2}{|c|}{ Taking diuretics } & \multicolumn{2}{|c|}{ Taking $\beta$ blockers } & \multicolumn{2}{|c|}{ Taking combination } & \multicolumn{2}{|c|}{ Not taking antihypertensives } \\
\hline & $\mathrm{n}$ & Mean (SD) & $\mathrm{n}$ & Mean (SD) & $\mathrm{n}$ & Mean (SD) & $\bar{n}$ & Mean (SD) \\
\hline \multicolumn{9}{|c|}{ Fasting blood glucose $(\mathrm{mmol} / \mathrm{l})$} \\
\hline $\begin{array}{l}38 \\
46 \\
50 \\
54 \\
60\end{array}$ & $\begin{array}{r}6 \\
19 \\
28 \\
16 \\
17\end{array}$ & $\begin{array}{ll}4 \cdot 3 & (0.6) \\
4 \cdot 1 & (0.6) \\
4 \cdot 2 & (0 \cdot 6) \\
4 \cdot 5^{*} & (0 \cdot 7) \\
4 \cdot 3 & (0.6)\end{array}$ & $\begin{array}{r}7 \\
26 \\
38 \\
20 \\
7\end{array}$ & $\begin{array}{lr}4 \cdot 1 & (0 \cdot 5) \\
4 \cdot 5^{* *} & (0 \cdot 7) \\
4 \cdot 5^{* * * *}(0 \cdot 8) \\
4.5^{*} \quad(0.9) \\
4 \cdot 3^{2}(0.7)\end{array}$ & $\begin{array}{r}12 \\
9 \\
19 \\
11 \\
8\end{array}$ & $\begin{array}{ll}4 \cdot 1 & (0.9) \\
4.0 & (0.5) \\
4.2 & (0.8) \\
4.6 * & (0.7) \\
4.3 & (0.6)\end{array}$ & $\begin{array}{r}276 \\
279 \\
244 \\
96 \\
28\end{array}$ & $\begin{array}{l}4 \cdot 0(0 \cdot 6) \\
4 \cdot 1(0 \cdot 6) \\
4 \cdot 1(0 \cdot 6) \\
4 \cdot 1(0 \cdot 6) \\
4 \cdot 2(0 \cdot 5)\end{array}$ \\
\hline \multicolumn{9}{|c|}{ Body mass index $\left(\mathrm{kg} / \mathrm{m}^{2}\right)$} \\
\hline $\begin{array}{l}38 \\
46 \\
50 \\
54 \\
60\end{array}$ & $\begin{array}{r}6 \\
19 \\
28 \\
16 \\
17\end{array}$ & $\begin{array}{ll}24 \cdot 1 & (1 \cdot 8) \\
25 \cdot 3 * * & (4 \cdot 4) \\
25 \cdot 8 * & (2 \cdot 9) \\
26 \cdot 4^{*} & (3 \cdot 5) \\
25 \cdot 8 & (3 \cdot 9)\end{array}$ & $\begin{array}{r}7 \\
26 \\
38 \\
20 \\
7\end{array}$ & $\begin{array}{lr}23.8 & (3 \cdot 0) \\
24 \cdot 4^{*} & (2 \cdot 3) \\
26 \cdot 7^{* * *} & (4 \cdot 6) \\
24 \cdot 6 & (5 \cdot 0) \\
26.8 & (4 \cdot 2)\end{array}$ & $\begin{array}{r}12 \\
9 \\
19 \\
11 \\
8\end{array}$ & $\begin{array}{ll}24 \cdot 1 & (2 \cdot 6) \\
23 \cdot 7 & (1 \cdot 9) \\
27 \cdot 5 * * * & (5 \cdot 6) \\
27 \cdot 4^{* *} & (5 \cdot 4) \\
25 \cdot 5 & (3 \cdot 9)\end{array}$ & $\begin{array}{r}276 \\
279 \\
245 \\
97 \\
28\end{array}$ & $\begin{array}{l}23 \cdot 1(3 \cdot 2) \\
23 \cdot 2(3 \cdot 2) \\
24 \cdot 1(3 \cdot 4) \\
24 \cdot 1(3 \cdot 3) \\
25 \cdot 9(2 \cdot 9)\end{array}$ \\
\hline
\end{tabular}

Significance compared with women not taking antihypertensive drugs: ${ }^{*} \mathrm{p}<0.05 ; * * \mathrm{p}<0.01 ; * * \mathrm{p}<0.001$.

Conversion: SI to traditional units-Glucose: $1 \mathrm{mmol} / 1 \approx 18 \mathrm{mg} / 100 \mathrm{ml}$.

showed glucose concentrations of $7.0 \mathrm{mmol} / 1(126 \mathrm{mg} / 100 \mathrm{ml})$ or more, according to the World Health Organisation's recommendations. ${ }^{6}$ In subjects receiving antihypertensive drugs registration was made with respect to start of treatment, type of antihypertensive drugs, and, when the antihypertensive treatment had been changed, the time when this change occurred. Body height was measured to the nearest $0.5 \mathrm{~cm}$ with the subject standing without shoes. Body weight was measured to the nearest $0.1 \mathrm{~kg}$ with a balance scale. The women wore only briefs when being weighed. Body mass index was calculated as weight $(\mathrm{kg}) /$ height $(\mathrm{m})^{2}$. Information about family history of diabetes was obtained in an interview.

\section{STATISTICAL METHODS}

Multivariate analysis was carried out using Pitman's non-parametric permutation test. ${ }^{7}$ The hypothesis of no differences between mean values was tested with Student's $t$ test. Differences in prevalences and incidences were studied by means of the $\chi^{2}$ procedure, according to Mantel-Haenszel, with one degree of freedom. ${ }^{8}$ In this way the effect of age as a confounding factor is minimised. Relative risk (risk ratio) and confidence limits of relative risk were calculated according to the Mantel-Haenszel estimation. ${ }^{8} 9$ Women of each age were studied separately (the ages of $38,39,40,41, \ldots 68,69$, $70,71,72$ years, altogether 35 periods of one year, during which the participants were at risk). In this way 856 patient years were recorded for participants taking diuretics as a sole drug, 664 patient years for women taking $\beta$ blockers as a sole drug, and 271 patient years for women taking a combination of diuretics and $\beta$ blockers (some of whom were taking other antihypertensive drugs in addition to diuretics and $\beta$ blockers). If those not participating in the follow up studies but from whom information was obtained are included the corresponding figures are 895,682 , and 281 respectively. Altogether 12798 control years were recorded for participants who did not take antihypertensive drugs during the 12 years ( 13855 when also including non-participants). Women who had taken antihypertensive drugs but not diuretics or $\beta$ blockers were not included in the statistical analysis. Differences and correlation coefficients were considered to be significant for $\mathrm{p}$ values of $<0.05$.

\section{Results}

Diabetes was diagnosed in 43 initially non-diabetic women between 1968-9 and 1980-1. At the time of the first study four of these 43 were aged $38 ; 10,46 ; 18,50$; eight 54 ; and three 60 . Of these 43 women, 25 were diagnosed as having diabetes while taking antihypertensive drugs and 18 while not.

A multivariate analysis was carried out in which age, initial fasting blood glucose concentration, and initial body mass index were taken into consideration as background variables. The correlation between antihypertensive treatment and incidence of diabetes was still significant when age, fasting blood glucose concentration, and body mass index were taken into consideration $(\mathrm{p}=0.00006)$.

Table III shows relative risk (with $95 \%$ confidence limits) for the incidence of diabetes mellitus in subjects receiving different types of antihypertensive treatment compared with in women who did not receive antihypertensive drugs. A substantially increased risk was observed for subjects taking diuretics, those taking $\beta$ blockers, and those taking a combination of diuretics and $\beta$ blockers. Those taking drugs other than diuretics or $\beta$ blockers were too few to permit conclusions. Those taking potassium saving drugs such as amiloride and spironolactone were also too few to permit separate conclusions, and these drugs were included among the diuretics. When the effects of diuretics and $\beta$ blockers were compared the relative risk was about the same: 1.4 in women taking $\beta$ blockers compared with those taking diuretics $(95 \%$ confidence interval $0 \cdot 5-4 \cdot 0)$ (including non-participants $1 \cdot 1$ (confidence interval $0 \cdot 4-3 \cdot 0)$ ); no significantly increased risk. The relative risk was found to be 2.5 for the combination of diuretics and $\beta$ blockers compared with diuretics alone $(95 \%$ confidence limits $0 \cdot 9-7 \cdot 3)$ (including non-participants $2.0 \quad(95 \%$ confidence limit $0 \cdot 7-5 \cdot 7)$ ). Again there were no significant differences.

TABLE III-Age adjusted relative risk (95\% confidence limits of relative risk in parentheses) in women taking diuretics, $\beta$ blockers, or a combination of diuretics and $\beta$ blockers compared within women not taking antihypertensive drugs

\begin{tabular}{|c|c|c|}
\hline Treatment & Relative risk & $\mathrm{p}$ value \\
\hline \multicolumn{3}{|c|}{ Non-participants in the follow up studies excluded } \\
\hline $\begin{array}{l}\text { Diuretics } \\
\beta \text { blockers } \\
\text { Diuretics and } \beta \text { blockers }\end{array}$ & $\begin{array}{r}3 \cdot 4(1 \cdot 5-7 \cdot 9) \\
5 \cdot 7(2 \cdot 6-12 \cdot 5) \\
11 \cdot 4(5 \cdot 0-26 \cdot 0)\end{array}$ & $\begin{array}{l}<0.01 \\
<0.001 \\
<0.001\end{array}$ \\
\hline \multicolumn{3}{|c|}{ Non-participants in the follow up studies included } \\
\hline $\begin{array}{l}\text { Diuretics } \\
\beta \text { blockers } \\
\text { Diuretics and } \beta \text { blockers }\end{array}$ & $\begin{array}{r}4 \cdot 6(2 \cdot 2-9 \cdot 5) \\
6 \cdot 1(2 \cdot 8-13 \cdot 3) \\
11 \cdot 5(5 \cdot 3-25 \cdot 0)\end{array}$ & $\begin{array}{l}<0.001 \\
<0.001 \\
<0.001\end{array}$ \\
\hline
\end{tabular}

Table IV shows some characteristics seen at follow up in 1980-1 of women who during the preceding 12 years had developed diabetes. Six of the women who were taking antihypertensive drugs and five of those who were not had had diabetes diagnosed as a result of the follow up study in 1980-1. Body weight exceeded $100 \mathrm{~kg}$ in five of the women taking antihypertensive drugs. There seemed to be no differences between women receiving different antihypertensive regimens in the variables presented in table IV except for a larger number of definitely overweight women among those taking antihypertensive drugs. As the fasting glucose concentrations show (table IV), diabetes was well controlled in most of the women. All but two in the group taking and all but three in the group not taking antihypertensive drugs had their diabetes controlled by diet alone or together with oral antidiabetic drugs.

\section{Discussion}

We found an appreciable increase in the incidence of diabetes in subjects taking diuretics or $\beta$ blockers or a combination of diuretics and $\beta$ blockers compared with women who were not taking antihypertensive drugs. No significant differences were observed between women taking diuretics and women taking $\beta$ blockers. As very few women in Gothenburg during these 12 years were taking any other antihypertensive drugs ${ }^{5}$ con- 
TABLE IV-Characteristics at the time of 12 year follow up in 1980-1 of women who, during the preceding 12 years or at examination in 1980-1, were diagnosed as having diabetes. (Body weights in parentheses denote that the figures were reported in an intervici, by women who did not participate in the study in 1980-1)

\begin{tabular}{|c|c|c|c|c|c|c|}
\hline $\begin{array}{l}\text { Case } \\
\text { Nio }\end{array}$ & $\begin{array}{c}\text { Age } \\
\text { (years) }\end{array}$ & $\begin{array}{l}\text { Duration } \\
\text { of diabetics } \\
\text { (years) }\end{array}$ & $\begin{array}{c}\text { Family } \\
\text { history } \\
\text { of } \\
\text { diabetes* }\end{array}$ & $\begin{array}{c}\text { Body } \\
\text { weight } \\
\text { (kg) }\end{array}$ & $\begin{array}{c}\text { Antidiabetic } \\
\text { treatment }\end{array}$ & $\begin{array}{l}\text { Fasting blood } \\
\text { glucose }\left(\mathrm{mmol}^{\prime} \mathrm{l}\right)\end{array}$ \\
\hline \multicolumn{7}{|c|}{ Taking diuretics } \\
\hline 1 & 50 & 3 & Yes & (90) & Tablets & \\
\hline 2 & 58 & 11 & No & $66 \cdot 1$ & Tablets & 8.9 \\
\hline 3 & 58 & 8 & $?$ & $119 \cdot 0$ & Tablets & 18.8 \\
\hline 4 & 58 & 0 & No & $123 \cdot 2$ & None & $7 \cdot 3$ \\
\hline 5 & 62 & 3 & No & 60.0 & Diet & $7 \cdot 6$ \\
\hline 6 & 62 & 0 & No & $60 \cdot 6$ & None & $6 \cdot 9$ \\
\hline 7 & 66 & 0 & No & $64 \cdot 0$ & None & $9 \cdot 3$ \\
\hline 8 & 66 & 10 & Yes & $73 \cdot 1$ & Tablets & $12 \cdot 3$ \\
\hline 9 & 72 & 6 & No & $92 \cdot 5$ & Diet & $4 \cdot 8$ \\
\hline \multicolumn{7}{|c|}{ Taking is blockers } \\
\hline 10 & 58 & 2 & Yes & $65 \cdot 2$ & Insulin & 13.5 \\
\hline 11 & 58 & 2 & Yes & $(45)$ & Insulin & \\
\hline 12 & 62 & 4 & Yes & 96.8 & Tablets & $10 \cdot 9$ \\
\hline 13 & 62 & 5 & Niv & 101.8 & Tablets & 8.0 \\
\hline 14 & 66 & 8 & Yes & 65.6 & Tablets & $5 \cdot 3$ \\
\hline 15 & 66 & 6 & Xo & $61 \cdot 3$ & Tablets & $6 \cdot 1$ \\
\hline 16 & 66 & 3 & Yes & $52 \cdot 2$ & Tablets & $4 \cdot 4$ \\
\hline 17 & 72 & 2 & No & 76.5 & Tablets & $7 \cdot 5$ \\
\hline \multicolumn{7}{|c|}{ Taking combination of diuretics and; blocker } \\
\hline 18 & 50 & 3 & Yes & $(140)$ & Tablets & \\
\hline 19 & 50 & 2 & Yes & 95 & Tablets & \\
\hline 20 & 62 & li & Nio & 81.0 & Diet & $8 \cdot 5$ \\
\hline 21 & 62 & $\begin{array}{l}1 \\
0\end{array}$ & Yes & 720 & None & $9 \cdot 7$ \\
\hline 22 & 62 & 0 & Yes & 114.0 & None & $9 \cdot 1$ \\
\hline 23 & 62 & 5 & No & $72 \cdot 0$ & Diet & $5 \cdot 7$ \\
\hline 24 & 66 & 0 & No & $86 \cdot 4$ & None & $6 \cdot 4$ \\
\hline 25 & 66 & 9 & No & $59 \cdot 7$ & Tablets & 4.5 \\
\hline \multicolumn{7}{|c|}{ Not taking antihypertensize drugs } \\
\hline 26 & 50 & 3 & Nio & (98) & Tablets & \\
\hline 27 & 58 & 6 & No & (63) & Insulin & \\
\hline 28 & 58 & 8 & No & (60) & Insulin & \\
\hline 29 & 58 & 6 & No & $80 \cdot 3$ & Tablets & $9 \cdot 2$ \\
\hline 30 & 58 & 9 & No & $62 \cdot 0$ & Tablets & $17 \cdot 0$ \\
\hline 31 & 58 & 7 & Yes & $68 \cdot 3$ & Tablets & 16.9 \\
\hline 32 & 62 & 6 & No & $52 \cdot 1$ & Insulin & 16.8 \\
\hline 33 & Dicd i & in 1976 & No & & & \\
\hline 34 & 62 & 0 & $\mathrm{No}$ & $84 \cdot 0$ & None & 6.5 \\
\hline 35 & 62 & 5 & No & 70.5 & Tablets & 3.8 \\
\hline 36 & 62 & 0 & No & 58.5 & None & $6 \cdot 3$ \\
\hline 37 & 62 & 0 & $\therefore i$ & 59.0 & None & 7.8 \\
\hline 38 & 62 & 4 & Yes & $80 \cdot 1$ & Tablets & $5 \cdot 7$ \\
\hline 39 & 62 & 1 & Yes & $67 \cdot 1$ & Dict & $6 \cdot 0$ \\
\hline 40 & 62 & 0 & Yes & 67.0 & None & $8 \cdot 8$ \\
\hline 41 & 62 & 0 & Yes & $100 \cdot 1$ & None & $8 \cdot 6$ \\
\hline 42 & Died i & in 1976 & Yes & & & \\
\hline 43 & 72 & 4 & Yes & $62 \cdot 2$ & Diet & $6 \cdot 9$ \\
\hline
\end{tabular}

* Diabetes among parents or brothers or sisters.

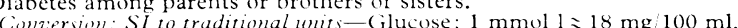

clusions concerning the incidence of diabetes could be drawn for only diuretics and blockers.

There are few recent data on the incidence of diabetes in subjects with untreated arterial hypertension as leaving arterial hypertension untreated is now considered to be ethically unacceptable. Previous studies have indicated an association between untreated hypertension and diabetes, as reviewed, for example, by Barrett-Connor et al ${ }^{11}$ and Drury, ${ }^{11}$ but the association was never as strong as that observed in the present study of hypertensive subjects taking antihypertensive drugs. We therefore feel justified in believing that an association exists between treatment with antihypertensive drugs and diabetes, at least as far as diuretics and \% blockers are concerned; final proof, however, is still lacking. It is also worth noting that in this respect our findings showed no difference between diuretics and 3 blockers.

Ever since diuretics were introduced as antihypertensive drugs their possible association with diabetes has been discussed, and many papers have been published on the possible relation between diuretics and impaired glucose tolerance or clinical diabetes. Such studies have been reviewed, for example, by our group $^{12}$ and by Furman ${ }^{13}$; interest has not, however, been focused on 3 blockers in the same way.

One main drawback of our study is that the subjects were not randomised to one or other drug. The drugs were given according to the individual doctor's clinical judgment. This necessitates caution when interpreting the results. With respect, however, to the appreciable differences observed in comparison with women not taking antihypertensive drugs and, in addition, the similarities before treatment between subjects who started different antihypertensive drugs, the results cannot be disregarded.

The main advantages of this study are that the women were representative of women in the general population, they were carefully followed up, a long follow up period was used, and the number of subjects disappearing from the study over the 12 years was small.

Our findings raise the important question of whether the results should be taken as an indication for avoiding diuretics and $\beta$ blockers in the treatment of arterial hypertension. Very limited information exists concerning the risk of diabetes when using other types of antihypertensive treatment, and we therefore think that other drugs must be shown to be different in this respect before they can be recommended, as being less diabetogenic, as drugs of choice in the treatment of arterial hypertension.

Despite the increased risk of clinical diabetes that we observed, we found that diuretics and 3 blockers caused few side effects during the long term follow up described in this paper. In addition, mortality was, if anything, lower among women who were referred for antihypertensive treatment at the time of the initial study than in other women of the same age in the general population. ${ }^{14}$ We therefore think that diuretics and 3 blockers are still the drugs of choice in the treatment of arterial hypertension.

The analyses and presentation of data were supported by grants from the Swedish Medical Research Council (27X-4578).

\section{References}

1 Mohler $\mathrm{H}$, Bravo EL, Tarazi RC. Glucose intolerance during chronic betaadrenergic blockade in man. Clin Pharmacol Ther 1979;25:237.

2 Bengtsson $\mathrm{C}$, Lennartsson $\mathrm{J}$, Lindquist $\mathrm{O}$, et al. On metabolic effects of diuretics and $s$-blockers. Results from a cross-sectional and longitudinal population study of women. Acta Med Scand 1982;212:57-64.

3 Bengtsson C, Blohme G, Hallberg L, et al. The study of women in Gothenburg 1968-1969-a population study. General design, purpose and sampling results. Acta Med Scand 1973;193:31 1-8.

4 Bengtsson C, Hallberg L, Hälstrom T, et al. The population study of women in Goteborg 1974-1975-the second phase of a longitudinal study. General

5 Sigurdsson JA. High blood pressure in women. A cross-sectional and a longitudinal

6 World Health Organisation. Report of the WHO expert committee on diabetes mellitus. WHO Techn Rep Ser 1980;646:1-80.

7 Bradley JV. Distribution-free statistical tests. Englewoud Cliffs, New Jersey: Prentice-Hall, 1968:68-86.

8 Mantel $N$. Chi-square tests with one degree of freedom; extensions of the Mantel-Haenszel procedure. Fournal of the American Statistical Association 1963;58:690-700.

9 Miettinen O. Estimability and estimation in case-referent studies. Am f Epidemiol $1976 ; \mathbf{1 0 3}: 226-35$

10 Barrett-Connor E, Criqui MH, Klauber MR, Holdbrook M. Diabetes and hypertension in a community of older adults. Am F Epidemiol 1981;113:276-84. 11 Drury PL. Diabetes and arterial hypertension. Diabetologia 1983;24:1-9. 11 Drury PL. Diabetes and arterial hypertension. Diabetologia 1983;24:1-9. hypertensive drugs. Acta Med Siand 1979; suppl 628:63-6.

Furman BL. Impairment of glucose tolerance produced by diuretics and other drugs. Pharmacol Ther 1981;12:613-49.

14 Sigurdsson JA, Bengtsson C, Lapidus L, Lindquist O, Rafnsson V. Morbidity and mortality in relation to blood pressure and antihypertensive treatment. A 12 -year follow-up study of a population sample of Swedish women. Acta Lied Scand 1984;215:313-22.

(Accepted 7 September 1984)

\section{Shredding of manuscripts}

From 1 January 1985 articles submitted for publication will not be returned. Authors whose papers are rejected will be advised of the decision, and the manuscripts will be kept under security for three months, to deal with any inquiries, and then destroyed by shredding. Hence we would prefer to receive for consideration photostats or copies produced by word processor (see $B M \mathcal{F} 13$ October, p 942), though we do, of course, still need three copies. 